\title{
ENTREVISTA A CARLOS FUENTES (1980)
}

\author{
POR \\ JOSE ANADON \\ University of Notre Dame
}

J. Anadón: Su libro La nueva novela hispanoamericana, que es clave para valorar su generación, ya tiene más de diez años. Pues bien: ese movimiento del llamado boom se hizo sobre la base de una novelística hispanoamericana con técnica narrativa moderna, pero no desapegada de la realidad humana y social viva de Hispanoamérica. ¿Qué agregaria usted hoy sobre su generación, que reunió a diversos escritores de diversas edades como Cortázar, Carpentier, Asturias, Rulfo, Vargas Llosa, García Márquez, Donoso, etc.?

C. Fuentes: En primer lugar, usted lo acaba de decir, es una generación un tanto excéntrica. Es una generación que no es una generación. En realidad, hay una coincidencia profunda en un cierto momento en la literatura hispanoamericana; yo diría que es un gran arco que se inicia con Borges y que aún no termina. No vemos todavía sus consecuencias finales, pero al mismo tiempo las obras producidas en estos años, digamos entre 1950 y 1980, no son aisladas, sin antecedentes, nacidas por generación espontánea. Creo que a partir de Borges, Onetti, Carpentier, en seguida a través de Paz y Cortázar — nacidos en 1914, y que son los grandes transmisores del movimiento moderno-, toda esta literatura simplemente le dio una organización y un relieve muy especiales a una experiencia que venía gestándose desde hacía muchísimo tiempo.

Quiero decir que lo que se llama el boom para mí no existe y no ha existido nunca: es una invención un poco de autores y libreros, porque es una etiqueta conveniente. El llamado boom, en realidad, es el resultado de una literatura que tiene por lo menos cuatro siglos de existencia y que sintió una urgencia definitiva en un momento de nuestra historia de actualizar y darle orden a muchas lecciones del pasado. En novelas como El siglo de las luces, o Cien años de soledad, o Corona- 
ción es evidente el intento de darle esta existencia al pasado para, en cierto modo, cancelar lo muerto y seguir caminando con lo vivo. Una novela ejemplar, en este sentido, creo que es Los pasos perdidos: Carpentier demuestra que varias etapas históricas, desde el instante del mito fundador, pueden coincidir perfectamente en un tiempo presente dado. En el caso de Borges, creo que el intento es aún más vasto, porque Borges trata de crear toda una segunda historia, como lo dice en uno de sus cuentos, una historia paralela que le dé cabida a todo lo que no ha sido en la América española, a través de una biblioteca ideal y finalmente de una historia ideal.

No creo que haya una dinámica que le diera enorme relieve a todas estas obras o que las hiciera a ellas o a sus autores islotes o seres de excepción, sino que, repito, están imbuidas de una gran tradición. En sí mismas, obras y autores establecen puentes para que la tradición continúe para lo que se ha de escribir en el futuro.

J. ANadón: ¿Quiénes le interesan más de los escritores posteriores a su generación?

C. FuEntes: De los escritores recientes de interés, creo que el cubano Reinaldo Arenas ha escrito varias espléndidas novelas. El mundo alucinante es una novela sobre esta gran figura de la picaresca política latinoamericana, fray Servando Teresa de Mier, un cura ilustrado de fines del siglo xvirI y principios del xIx, mexicano, imbuido de las ideas de la Ilustración, que participó en el Congreso de Cádiz, en el Congreso liberal de España de 1812 y que llevó una vida digna de un Guzmán de Alfarache de alcurnia, y teólogo, además, que culminó con la organización de su propio entierro, al cual asistió él mismo antes de desaparecer del mundo de los vivos. Es decir, cumplió su decisión de ser un sacerdote de la Ilustración, un hombre capaz de secularizarlo todo, incluso el testimonio de su propia muerte. Es una gran novela de Reinaldo Arenas, junto con Celestino antes del alba, que es una de las más hermosas novelas que se han escrito sobre la niñez, la adolescencia y la vida en Cuba, para un chico que nació en los años cuarenta.

Hay Gustavo Sainz, un escritor que se octpa mucho del perfil cómico de la ciudad de México. Tiene mucho de los atributos cómicos de la literatura anglosajona, que ha entendido bien. Sainz ha asimilado bien a Heller, por ejemplo. Y José Agustín, que se ocupa de lo que en México se ha llamado «La Onda», es decir, la generación más joven de muchachos rocanroleros, drogadictos, todo el mundo de los sesenta, básicamente.

Pero yo lo que veo y me parece positivo es que una vez más la relación entre la poesía y la novela es sumamente clara, esclarecedora y 
enriquecedora en la América Hispana. Yo creo que antes de la ola de novelistas que usted ha mencionado, lo que nos precede a nosotros es una enorme riqueza de la poesía. Estoy seguro de que cualquier novelista hispanoamericano del llamado boom dirá que lo que más influyó en nosotros, en nuestra formación literaria, fueron los poetas de lengua española. Lo que nos alimentó fue la poesía escrita por la generación anterior, es decir, la poesía de Pablo Neruda, de Gabriela Mistral, Vicente Huidobro, César Vallejo, Javier Villaurrutia, López Velarde, Leopoldo Lugones. E1 problema ha sido siempre el mantenimiento y enriquecimiento de la lengua española, de comprensión de que finalmente la casa y el suelo común del lenguaje se llama "poesía»; y un poco como Anteo, cuando se quiere tomar contacto con la tierra para recobrar fuerzas, hay que tomar contacto con la poesía. Lo que siento es que hay una enorme y magnífica generación de poetas latinoamericanos que está sucediendo a los novelistas del boom, tomando el relevo un poco de lo que hicimos los novelistas, y estoy seguro de que estos poetas a su vez van a alimentar otra generación de novelistas que ni siquiera nos sospechamos. Estoy pensando, para no hablar más que de mi país, que es lo que conozco mejor, en poetas como Gerardo Denise y David Huerta, y otros.

J. ANADón: Sus últimas novelas tocan asuntos politicos y económicos, entre otros temas; anteriormente, en su obra teatral Todos los gatos son pardos, la última escena transcurre en el presente y los conquistadores son norteamericanos. ¿Siente viva esa amenaza?

C. Fuentes: ¡Pero cómo no! México tiene petróleo. Usted lee las memorias de Kissinger, quien dice: «Nosotros derrumbamos al gobierno de Allende en Chile porque ese gobierno no tenía verdadera legitimidad. Era un gobierno con una pluralidad simplemente, y estábamos convencidos de que finalmente iba a ser un gobierno contrario a los intereses de los Estados Unidos.» Pues yo me pregunto: ¿Cuál era la legitimidad de Anastasio Somoza o de Rafael Trujillo? ¿Por qué no se puede hacer lo mismo en México, donde los intereses que se juegan son mucho más graves que los que se jugaban en Chile con la Unidad Popular? Chile tuvo un gobierno democrático hasta el día de la muerte de Salvador Allende. Tuvo el gobierno más democrático de la América Latina. La prensa se publicaba, los partidos políticos funcionaban, el Parlamento se reunía. Ese gobierno era una amenaza para los Estados Unidos, a los ojos de Richard Nixon y Henry Kissinger. Yo me pregunto: ¿Qué se puede crear como política, qué se le puede proponer al público norteamericano para apoderarse de una reserva petrolera de 200.000 millones de barriles? Se pueden inventar muchas cosas, crear muchos incidentes: 
se pueden hundir muchos Maines, organizar muchos Pearl Harbors, crear nuevos Alamos.

Quiero hacerle una distinción entre lo que critico en la política exterior de los Estados Unidos y la admiración que yo tengo por este país, por su cultura, por su literatura. Si no fuera por otra cosa, puesto que soy escritor. Las culturas, por su naturaleza, deben estar comunicadas y deben generosamente participar sus valores, las unas de las otras. Pero estamos hablando de una política muy concreta de explotación y avasallamiento, perpetrada por una de las grandes potencias mundiales. El único paralelo que yo encuentro para la destrucción del gobierno de Salvador Allende en Chile es la política soviética de destrucción del gobierno de Alexander Dubaceć en Checoslovaquia.

J. ANADóN: ¿Cree usted que dentro de la nueva situación económica de México la vida artística e intelectual va a continuar tan ligada al régimen político de los últimos años, o si se va a cambiar?

C. Fuentes: Usted me está haciendo una pregunta fundamental sobre un tema fundamental que afecta no sólo a México, sino a toda la América Latina: es el problema de la sociedad civil en la América Española. Max Weber decía que, en mayor o menor grado, todos los países de la América Latina, sin excepción, son gobernados por regímenes de tipo paternalista y patrimonialista. No son propiamente ni sistema feudal, ni sistema capitalista, ni sistema socialista. Son haciendas más o menos dominadas por pequeños «cliques» de gente con sistemas de nepotismos, favoritismos, cuadros administrativos muy endebles. En mi propio país, que tiene una cierta experiencia en la formación de la Administración Pública, yo no podría decir que hay más de dos ramas de servicio civil verdaderamente establecidos, que son las Relaciones Exteriores y la Secretaría de Hacienda (el Ministerio de Finanzas). Lo demás está sometido a este régimen de favoritismos, de cambios, típico de la América Latina y del sistema patrimonialista. La América Latina no ha tenido sociedades civiles; en esto nos parecemos mucho a Rusia. La sociedad civil europea yo creo que nació del conflicto ante el poder espiritual y el poder temporal en la Edad Media; los conflictos entre los príncipes y los papas. El hecho de que Enrique IV fuese enviado a Canosa por el papa Bonifacio VIII, que se hubiera opuesto a él, creó una tensión constante en la vida política europea, que finalmente permitió la creación de una sociedad civil y de formas democráticas. En Rusia esto jamás existió, como usted sabe; allí hubo una identificación total del poder espiritual, civil y político, lo que se llamó césaropapismo. El matrimonio de Iván IV con Soé Paleóloga, la última heredera de Bizancio, convierte a Moscú en la Tercera Roma, como se autodenominó - y no habrá una 
cuarta, dice Dostoievski-. Esta Roma moscovita está dominada por la idea de la inseparabilidad del poder político y el poder espiritual: quien tiene uno tiene el otro: lo tenían los zares y lo tiene Breznef. No hay sociedad civil; es la crítica que dirigía Gramsci a la revolución soviética. No puede haber verdadero socialismo donde no hay una sociedad civil fuerte. La hay en Italia, en Alemania, en Francia. Por esto Marx pensó que la revolución socialista tendría lugar en países de gran desarrollo industrial, de gran desarrollo de la burguesía y de la sociedad civil. Los Estados Unidos tiene este desarrollo de la sociedad civil. Latinoamérica no lo tiene.

Entonces, su pregunta me hace pensar que en mi país no sólo el escritor, sino el profesionista - cualquier persona egresada de las universidades con una profesión, con una cierta preparación técnica-, tiene que servir $o$ al Estado o a la iniciativa privada. La iniciativa privada mexicana sigue siendo una iniciativa privada colonialista, subordinada a intereses de las corporaciones de los Estados Unidos fundamentalmente. Si se le sirve a ellas, no creo que se esté sirviendo a una sociedad civil. La otra alternativa es servir al Estado, al sector público, con lo que representa de defensa de la nacionalidad, de la integridad de. México, pero con su enorme corrupción también. Entonces es estar entre Escila y Caribdis; es sumamente difícil.

Lo que ha pasado, que es positivo, es lo siguiente. Como se sabe, en México, en 1968, hubo un estallido de descontento que fue reprimido ferozmente en la Plaza de las Tres Culturas: la matanza de Tlatelolco del 2 de octubre de 1968, en la que perecieron trescientos o cuatrocientos estudiantes. La matanza de 1968 reveló un malestar en México que el régimen político no sospechaba. El régimen político se lo había pasado autofelicitándose, aplaudiéndose a sí mismo, hablando del milagro mexicano, diciendo que México era un país sin problemas: playas maravillosas, Acapulco, rascacielos, muchos Volkswagen, Kelvinators, un país de clase media en ascenso. ¿Dónde estaban los problemas? Los problemas estaban ahí, en la propia clase media, porque el movimiento del 68 no fue un movimiento obrero y campesino. Fue de estudiantes de clase media. Este malestar inmediatamente puso al país ante una disyuntiva de democratizar en cierta forma o de reprimir. El gobierno de Díaz Ordaz decidió reprimir, y con mano muy firme. Es decir, que México llevaba la dirección de Chile, o Argentina, o Uruguay. La virtud del gobierno de Echeverría fue prescindir de la opción represiva, sin acabar por crear una democracia, ni mucho menos - cosa que no se improvisa de la noche a la mañana-, pero por lo menos de permitir un respiro para la reorganización de las fuerzas democráticas. Con el 
gobierno de López Portillo esto se ha consolidado, en cierto modo, gracias a la reforma política, que actualmente le da representación en el Congreso a los partidos de izquierda; y esto es muy importante, porque el gobierno mexicano desde siempre ha tratado de identificarse con la izquierda, de aparecer como un gobierno revolucionario. Es decir, a mi izquierda no hay nada: yo soy la izquierda. Con la reforma política de hace unos años el gobierno ha reconocido que hay una izquierda a su izquierda. El partido comunista ha sido legalizado y tiene una representación importante en el Congreso. Otro grupo de izquierda no comunista, «El partido mexicano de los trabajadores», también ha sido reconocido y tiene representación de la misma manera que la tienen otros grupos a la derecha del PRI. Es decir, el PRI no aparece ya como el portaestandarte de la revolución. El PRI sacrifica una buena parte de su legitimidad, que estaba profundamente identificada con el hecho de que fue el protagonista de la revolución mexicana. Ahora no se atreve ya a decir1o; esto es una ganancia en el sentido de la creación de una sociedad civil política diversificada y plural, que todavía no existe en México, pero ¿dónde existe en la América Latina? Existía en Chile, antes, y por eso nos lamentamos tanto de lo que pasó en Chile. Pero resulta que la sociedad chilena fue endeble frente a las amenazas. Entonces yo creo que, por lo menos en México, hay la decisión de no caer en la trampa de un régimen militar opresivo; no es perfecto, ni mucho menos, pero tampoco es de represión, tortura o silenciamiento; cada día más nos deja a los ciudadanos ganar posiciones políticas independientes y acaso, a través de ello, se acabará por crear una sociedad civil. Pero esto es algo sumamente difícil, porque no hay los antecedentes.

Los regímenes mexicanos que han querido practicar la democracia representativa son contadísimos. Podríamos decir que son: el gobierno de Vicente Guerrero, entre 1823 y 1827, después de la caída del emperador Iturbide; el régimen de la república restaurada de Benito Juárez, después de la derrota de los franceses y Maximiliano de Augsburgo, antes de que Porfirio Díaz tomara el poder y creara una nueva dictadura, y el régimen de Francisco Madero, que fue destruido por la libertad que permitió, por el ridículo con que la prensa lo cubrió. Madero dio todas las libertades democráticas, pero no tocó la estructura colonial de México, al ejército, a los latifundistas, ni a la Iglesia. $Y$ todos se juntaron para destruirlo, después de un año y medio de gobierno. Desde entonces hay the awareness de no saber cuándo se da, en qué momento, a quiénes. Son cosas que hay que ir ganando poco a poco, en un proceso que por desgracia toma mucho tiempo. 
J. ANAdón: México siguió muy de cerca e influyó directamente en los acontecimientos de Nicaragua, junto con los países del Pacto Andino, para encontrar una solución de tipo democrático. ¿Qué piensa usted del futuro de una relación politica continuada entre México, que ahora entra a una etapa distinta de mayor poderio económico e industrial, con el grupo de tipo preponderadamente democrático de la CEA?

C. Fuentes: Bueno, yo creo que México no es más poderoso que algunos países del Pacto Andino, como Venezuela. Es bastante relativo; sobre todo que ningún país latinoamericano es poderoso al lado de los Estados Unidos. Usted sabe que la ciudad de Los Angeles tiene un presupuesto mayor que el de la República Mexicana. Los Estados Unidos, aun con crecimiento cero, por la complejidad de toda su estructura económica, sin moverse, cada año añade a su economía creo que doce Méxicos, cinco Gran Bretañas, tres Francias. Pero los Estados Unidos tienen otra dimensión.

Lo que ha pasado me parece muy interesante. Recordemos el enfrentamiento de hace veinte años entre Cuba y los Estados Unidos; fue entre Goliat y David; no había comparación. Cuba fue dejada sola por la América Latina. Hubo intereses en los Estados Unidos que lo condujeron a la ruptura con Cuba: no querían, o no fueron capaces de aceptar que un país fuese socialista en la América Latina. Además de ser socialista, tenía que ser satélite de la Unión Soviética, para desacreditar la solución socialista. Y así sucedió. Esta lección yo creo que fue aprendida por la América Latina.

En el caso de Nicaragua, lo que ha pasado es que el gobierno revolucionario sandinista de Nicaragua, desde el principio, antes de tomar el poder, estaba rodeado por el apoyo, el consejo, la presencia de países como México, los países del Pacto Andino que usted ha mencionado, Costa Rica, Panamá. Los nicaragüenses saben que están rodeados y apoyados por estos países, pero los Estados Unidos lo saben también. De tal suerte que no pueden adoptar las actitudes frente a Nicaragua que tuvieron ante Cuba, porque esta vez el país pequeño no está solo, y esto colorea las actitudes mutuas de una manera que me parece sumamente positiva y que crea un nuevo conjunto de valores. Pero la pregunta fundamental permanece: ¿puede Nicaragua ser socialista sin que los norteamericanos la obliguen a ser parte del campo soviético? ¿Son capaces los norteamericanos de respetar una experiencia socialista en una nación latinoamericana, sabiendo que no tiene por qué convertirse en un satélite ruso? Mire usted, yo estaba en La Habana cuando vino la ruptura real, y vino por una cosa muy clara: los Estados Unidos se negaron a venderle más petróleo a Cuba y la bloquearon. Yo estaba ahí el día 
que empezaron a entrar los tanques rusos a La Habana. Para subsistir, la revolución tenía que recibir petróleo, viniera de donde fuera.

Hoy estamos llegando a una serie de soluciones nuevas, interesantes, que también se encaminan a la integración económica de la América Latina, precisamente en el tema del petróleo. México le ha estado vendiendo petróleo a España, en tanto que Cuba recibe su petróleo de la Unión Soviética. Uno de los efectos positivos de la visita de Fidel Castro a México, en el mes de marzo o abril del año pasado, es que se ha llegado a un acuerdo en virtud del cual México enviará a Cuba, que está cerca, el petróleo que le enviábamos a España; y la Unión Soviética le enviará a España, que también está cerca, el petróleo que antes le enviaba a Cuba. Además de que it makes economic sense, por un lado, y por el otro abre una avenida para una mayor integración de Cuba en el sistema económico latinoamericano.

Usted sabe que los presidentes Echeverría y Carlos Andrés Pérez crearon una organización de la que se habla poco, pero que cumple una tarea fundamental, y sobre todo una tarea de reserva que está ahí lista, que es la SELA (Sistema Económico Latino Americano), que tiene su sede en Caracas y que excluye a los Estados Unidos; es exclusivamente latinoamericano, para promover este tipo de mayor integración y ayuda entre nuestras naciones. Está funcionando a varios niveles. Por ejemplo, en el caso de Jamaica y México, para la explotación de la bauxita. Hay una flota común del Caribe, con participación de todos los países con costas en el Caribe. Se han hecho varias cosas, y yo creo que a través de estas iniciativas se puede asegurar que en el futuro haya una integración mayor, porque, le repito a usted, el problema no es México contra el Pacto Andino o México ante el Pacto Andino. El problema sigue siendo la América Latina frente a los Estados Unidos.

J. Anadón: ¿Cómo ve usted los estudios hispánicos en Estados Unidos o la educación universitaria en general?

C. Fuentes: Pues no los conozco tan, tan bien. Pero sí veo que se leen muchos autores hispanoamericanos, se escriben muchas tesis; hay interés y conocimientos grandes; yo estoy muy agradecido porque mi editor me manda cuentas en las que veo que mis libros se venden mucho en las universidades. Es tan vasto el mundo universitario norteamericano, que el interés por la literatura de la América Latina lo convierte en uno de los puntales de esa misma literatura. Uno de los públicos más extensos que tenemos los escritores latinoamericanos está en las universidades de los Estados Unidos. Yo siempre me pregunto por qué teniendo tan buenas universidades luego cometen tantos errores de política exterior. Como si no hubiera información alguna. Nadie sabía que Viet- 
nam siempre ha sido la barrera contra la expansión china en el sureste asiático; que Vietnam, por ejemplo, ha sido el papel histórico de Indochina... Es rarísimo.

Creo que hay un problema fundamental en cuanto a la educación norteamericana, y es su orientación excesivamente pragmática. Una hija mía ha hecho sus estudios en francés, y veo que a los diez años de edad había leído a Molière, a La Fontaine y a Corneille, y conocía la lengua francesa perfectamente. Tengo la impresión de que en los Estados Unidos no se le presta suficiente atención al estudio de la lengua, al conocimiento de la literatura como base para hacer cualquier cosa en el mundo. Un médico, un ingeniero, un abogado que no conoce bien su lengua va a ser un mal médico, ingeniero y abogado. No va a saber comunicarse ni pensar bien, porque también se leen libros para aprender a pensar. Un profesor alemán mío decía que «los alemanes hacemos buen jabón porque Kant escribió La crítica de la razón pura». Cuando se considera que la literatura es algo marginal, para una élite, un entretenimiento, resulta una mentira. La lengua es hasta ahora el medio de comunicación natural, normal, el más rico, el más sensual, además, entre los hombres y las mujeres, y creo que es la base para pensar bien y actuar con inteligencia en el mundo. Marshall McLuhan en el año 1965 habló del fin de la era de Gutenberg y de la muerte eventual de la palabra escrita, de los libros, etc. Se le hizo notar que para comunicar estas ideas tenía que usar libros, escribirlos.

Yo siento que hay una especie de saturación, una especie de inteligencia, respecto a lo que los medios tecnológicos y los medios masivos de comunicación pueden darnos a todos. Es como haber estado engolosinados con un gadget nuevo, un regalo de Navidad bonito. Viene un momento en que yo siento que los seres humanos tienen que estar solos con un libro, con esa comunicación que proporciona un libro; que no todo puede ser espectáculo y diversión en el mundo. Es una capacidad absolutamente delirante que tiene el mundo occidental para convertirlo todo en entertainment. Sobre todo en los Estados Unidos, everything is entertainment, hasta Eva Perón. Creo que si no ha pasado todavía, va a terminar por saturarnos.

En Francia sí he visto la experiencia más de cerca. Además de que la televisión francesa es pésima, el hecho es que ha habido este proceso de saturación. Los jóvenes buscan más y más; sí que no van a abandonar la televisión, el cine; pero están reservándole más tiempo de sus vidas a leer libros. Mi editor francés, Gallimard, olió la saturación con los medios masivos de comunicación, y dijo: «Voy a publicar una edición que se llame 'L'imaginaire', en la que voy a rescatar libros verda- 
deramente de la imaginación que no han estado publicados en Francia.» ¿Qué libros? Por ejemplo, Absalom-Absalom, que estaba agotado en Francia desde hace treinta años; Benito Cereno, de Melville; el Pedro Páramo, de Juan Rulfo; obras de Francis Carco, de André Pierre de Mandiarges y otros escritores franceses. Los tirajes han sido de cien y ciento cincuenta mil ejemplares; es decir, hay un público para todo esto. Yo no creo que la palabra ni la literatura estén muertas.

J. ANAdón: ¿Siente particular predilección por alguna de sus obras?

C. Fuentes: Por ninguna. Cuando uno se siente satisfecho ya no quiere escribir más. Yo estoy insatisfecho siempre, totalmente, y para mí esto es fundamental, como resorte para seguir escribiendo. Además, creo que inconscientemente busco siempre que las obras sean imperfectas. Debe ser porque la imperfección da margen al riesgo. Si uno no es capaz de asumir riesgos al escribir, yo creo que las obras pueden salir más perfectas, porque la perfección se juzga sobre un modelo previamente establecido. El elemento de riesgo, que para mí es fundamental en la literatura, se toma a partir de la imperfección solamente. Ahora, desde el momento que escribo novelas que son imperfectas, que las busco así porque asumen riesgos, abro el camino para escribir otras obras igualmente imperfectas, en las que pueda asumir nuevos riesgos. Y si no hiciera esto, no sabría vivir, me habría pegado un tiro ya. Entonces, no puedo contestar su pregunta, porque además yo creo que he escrito una sola novela, con distintos capítulos, un poco una comedia mexicana, a lo Balzac, que tiene muchos capítulos y muchos aspectos, muchas distintas aproximaciones, como en La cabeza de la hidra, por ejemplo. En esa novela sentí yo que era la única manera de abordar el tema del petróleo y las transformaciones que está operando en la vida mexicana. Es tan diferente como las otras novelas mías; como lo es, en el caso de Balzac, El diputado de Arsis, novela sobre la vida política francesa, estrictamente. Como es diferente de una novela metafísica como Louis Lambert o La piel de zapa. De modo que mis novelas son un mural compuesto de muchos mosaicos.

Iría más lejos: García Márquez dice que no se ha escrito no más que una novela en la América Latina, con un capítulo escrito por Cortázar en la Argentina, otro por Carpentier en Cuba, otro por Vargas Llosa en Perú, etc. Pero es una sola novela, y habría que leerla de esa manera, como una sola vasta novela de varios cientos de miles de páginas, posiblemente. 